\title{
Review Article \\ Extreme Environmental Stress-Induced Biological Responses in the Planarian
}

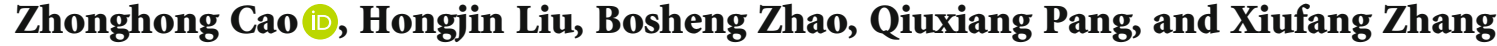 \\ School of Life Sciences, Shandong University of Technology, 266 Xincun Western Road, Zibo 255049, China \\ Correspondence should be addressed to Zhonghong Cao; zhcao@sdut.edu.cn
}

Received 3 April 2020; Accepted 25 May 2020; Published 11 June 2020

Guest Editor: Lei Zhao

Copyright ( 2020 Zhonghong Cao et al. This is an open access article distributed under the Creative Commons Attribution License, which permits unrestricted use, distribution, and reproduction in any medium, provided the original work is properly cited.

\begin{abstract}
Planarians are bilaterally symmetric metazoans of the phylum Platyhelminthes. They have well-defined anteroposterior and dorsoventral axes and have a highly structured true brain which consists of all neural cell types and neuropeptides found in a vertebrate. Planarian flatworms are famous for their strong regenerative ability; they can easily regenerate any part of the body including the complete neoformation of a functional brain within a few days and can survive a series of extreme environmental stress. Nowadays, they are an emerging model system in the field of developmental, regenerative, and stem cell biology and have offered lots of helpful information for these realms. In this review, we will summarize the response of planarians to some typical environmental stress and hope to shed light on basic mechanisms of how organisms interact with extreme environmental stress and survive it, such as altered gravity, temperature, and oxygen, and this information will help researchers improve the design in future studies.
\end{abstract}

\section{Introduction}

Planarians are bilaterally symmetric metazoans of the phylum Platyhelminthes. They have well-defined anteroposterior and dorsoventral axes and have an anterior cephalic region which contains the brain and a pair of eyespots, a central region which includes the pharynx and the mouth, and a posterior tail region. Despite their relatively simple morphology, planarians have a highly structured central nervous system (CNS) and feature a true brain which consists of all neural cell types and neuropeptides found in vertebrates [1-3]. They have roughly $30 \%$ adult stem cells $[4,5]$ and possess an extensive potential of regeneration. Planarians are one of the few animal species that can easily regenerate their head including the complete neoformation of a functional brain within seven days after decapitation [6-9]. Moreover, planarians share more genes with vertebrates compared with other popular model organisms such as Drosophila melanogaster or Caenorhabditis elegans [10]. All of these make planarians a reliable and popular model in the field of developmental, regenerative, and stem cell biology.
Exploring and living somewhere beyond the Earth are always two of the dreams of humans. It means that humans had successfully walked the first step to explore the space when Soviet cosmonaut Yuri Alekseyevich Gagarin had finished his journey of 89 minutes of orbiting the planet in his space capsule, on April 12, 1961. Then, more and more astronauts successfully finished their spaceflight, and their dwell time in space also is longer and longer. But the bad news is that astronauts on a long-term mission have problems upon returning to Earth, such as bone density loss; muscle atrophy; cardiovascular and hematic changes; metabolic, endocrine, and sleep disturbances; and rapid senescence [11, 12]. These actual and potential physical effects on the body mainly come from extreme environmental stress outside the Earth, such as altered gravity, temperature, and oxygen. Then, if we want to provide a habitat that can keep organisms in it living, it is necessary to understand what the biological responses of extreme environmental stress induce. We ethically cannot directly test the impact of environmental stress on humans. We need to use appropriate animal models to learn the adaptation of mammals about environmental stress. 
Planarians not only can easily regenerate the lost parts but also can survive a series of altered environment. These make the planarian an ideal model organism, help us to understand how extreme environmental stress impacted the biological responses of organisms, and help us to find out the conserved molecules and mechanisms that support organisms to survive extreme environmental stress. There are reports that environmental stress can impact the structure of cells, intercellular communication, regeneration, embryonic development, and even immunological responses [13-18]. In this review, we will summarize the impact of some typical environmental stress for the planarian and hope to shed light on basic mechanisms of how organisms interact with extreme environmental stress and survive it, such as altered gravity, temperature, and oxygen. And this information will help researchers understand the basic mechanisms and improve the design in future studies.

\section{Physiological Effects of Altered Gravity and Magnetic Field}

Later missions showed that space travel could be tolerated by humans, but microgravity will trigger lots of physiological responses and even some pathological reactions. If we want to keep organisms healthy and happy in altered gravity, we need to use appropriate animal models to learn the effects of altered gravity. Planarian flatworms possess remarkable regeneration ability and share more genes with vertebrates than other popular model organisms such as Drosophila melanogaster or Caenorhabditis elegans [10], so it can minimize background interference, and becomes an ideal model to learn the effects of altered gravity. This part will summarize the most relevant data from exposure of planarian to altered gravity and magnetic levels obtained through ground-based facilities or board spaceflights, sounding rockets, satellites, or space stations. We will discuss the different effects of altered gravity on planarian, including the impacts on regeneration ability, embryonic development, phototaxis response, moving behavior, and transcriptomic information.

2.1. The Regeneration and Fission Ability. In the study of Gorgiladze et al., they cut 60 freshwater planarian Girardia tigrina 12 to $14 \mathrm{~h}$ before the spacecraft starts from the Baikonur launching site. In their experiment, they cut off the planarians before and after the pharynx and collected the different fragments into $20 \mathrm{ml}$ polyethylene vials which are filled with freshwater, respectively. The air temperature of the RS ISS service module ranged from 19 to $21^{\circ} \mathrm{C}$, as determined by telemetry. After 10 days of journey, they found that all the amputated body parts regenerated the lost parts, and the morphometric parameters of regenerated fragments were not different from those of the control fragments. And yet, the regenerated planarians were smaller than the original "maternal" planarians until the 18th to 20th day after dissection [19].

Whole-mount and amputated fragments of Dugesia japonica planarian had been collected into sealed $50 \mathrm{ml}$ tubes with $50 \% / 50 \%$ air/water, then had been sent to the ISS for one month. Results showed that only the whole worms are divided spontaneously which had been sent into space; the fission rate changed from 1.3 to 1.75 . They did not find a fission phenomenon in other samples. Yet, the authors cautioned that the worms in space unavoidably experienced somewhat higher temperatures at some time periods, so we should keep admonishing for this result. After returned two months later, the number of worms that had gone to space was slightly less than the worms that were maintained on Earth [20]. For the amputated worms, the size is similar between the two groups after the space journey. And after two months of culture, the worms exposed to space grew more slowly than the Earth-only controls. The most striking phenomenon is that they found that one of the 15 pharynx fragments from space had regenerated two heads (see Figure 1), and after amputating the two heads, the headless middle fragment regenerated into a double-headed phenotype [20]. But we need to note that pharynx fragments left on Earth did not survive the duration of the mission in this work. Levin et al. thought that people should be cautious about this result; maybe it is not really induced by microgravity [21].

Teresa et al. performed their experiment in the European Space Research and Technology Centre, Noordwijk, The Netherlands. In their work, they researched the impact of simulated microgravity on the regeneration of Schmidtea mediterranea. They get simulated microgravity by means of the random positioning machine (RPM) set at a speed of $60 \%$ and $10 \%$, and their results demonstrate that RPM $60 \%$ led to the death of trunk planarians, whereas planarians loaded into the $10 \%$ RPM machine appeared normally regenerated (have the normal eyes and the normal CNS and have similar mitotic activity). Moreover, they found that all planarians live and correctly regenerated the corresponding lost parts on day 5, which indicates that planarians do not die soon when sensing the effects of the $60 \%$ RPM but after having regenerated the main structures. They hypothesized that there are rheoreceptors in the head of planarians, and when they regenerated the whole head, they can sense the water currents which are produced in the $60 \%$ RPM and induce death [16]. It is necessary to analyze the effect of $60 \%$ RPM rotation for intact animals and definitely corroborate this hypothesis. These results demonstrate that it is not the simulated microgravity but the specific setting of rotation of the $60^{\circ} / \mathrm{s}$ RPM that induced the death of planarians.

They also examined the impact of hypergravity on regeneration of Schmidtea mediterranea and simulated hypergravity $3 \mathrm{~g}, 4 \mathrm{~g}$, and $8 \mathrm{~g}$ by a large diameter centrifuge (LDC). Under $3 \mathrm{~g}$ and $4 \mathrm{~g}$ hypergravity, planarians can regenerate missing tissues, but the proliferation rate was decreased. Under $8 \mathrm{~g}$ hypergravity, only the larger trunk planarian fragments can regenerate the lost part, and the small planarian fragments cannot successfully regenerate the corresponding part. Although the molecular reason for this effect has not been found, the decreased proliferative rates suggest that gravity could affect the actin cytoskeleton and the assembly of microtubules, just as it happens in other organisms [2224]. Meanwhile, they found that changed gravity had affected the fission rate of planarians, and the number of smaller 


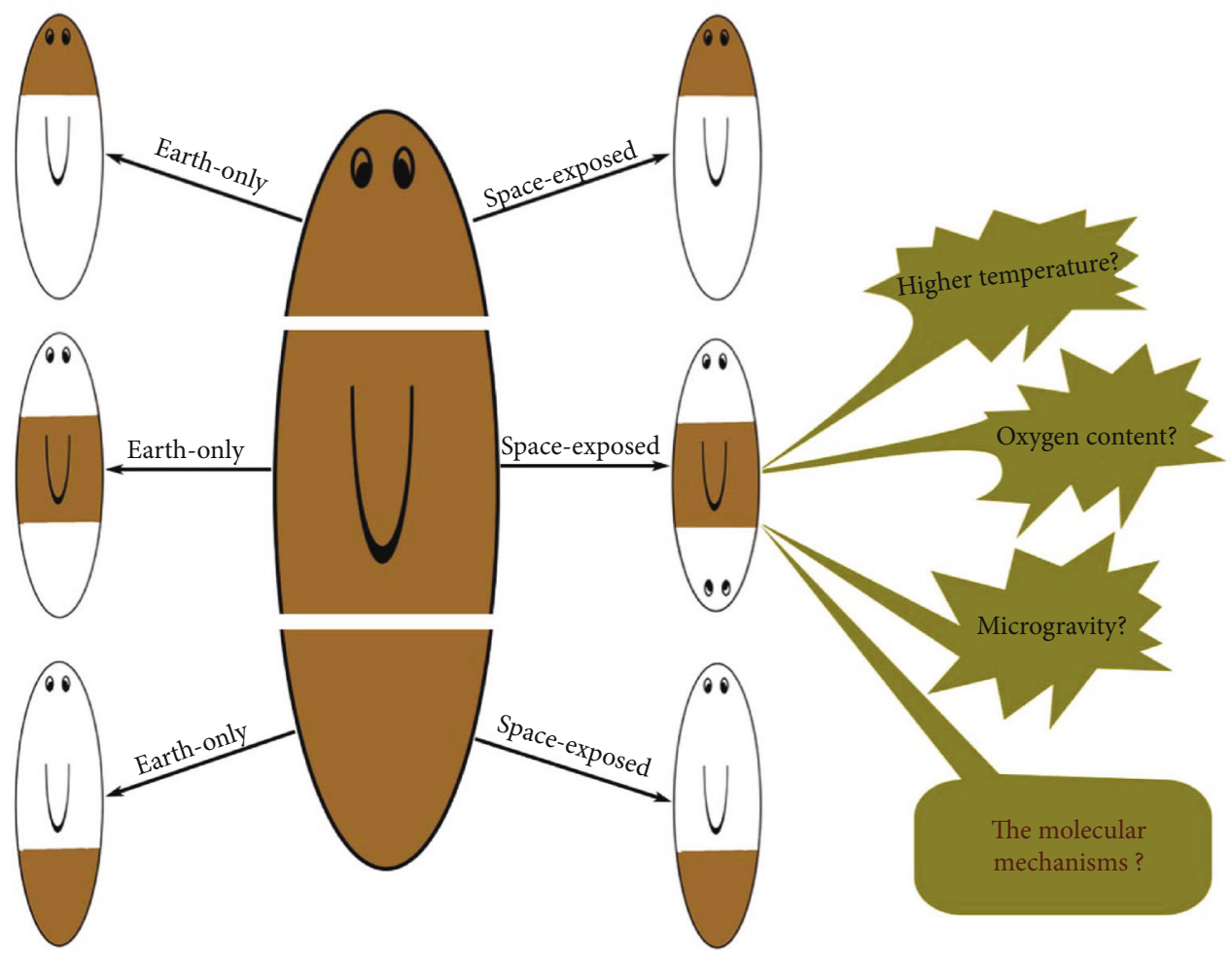

FIGURE 1: The effects of changed gravity on regenerated tissues in planarian. The left panel indicates that Earth-only planarian fragments regenerated the lost part. The right panel indicates that space-exposed head and tail fragments regenerated the lost parts, but the truncated middle planarian regenerated two heads. The immediate cause and molecular mechanisms are not well known for this phenomenon. Brown marks the original tissue, and white marks the regenerated parts.

fragments was significantly higher in LDC $4 \mathrm{~g}$ planarians compared with the rest of the groups.

The study about 3-6 d old cocoons of Schmidtea polychroa showed that all cocoons in RPM $60^{\circ} / \mathrm{s}$ or LDC $3 \mathrm{~g}$ conditions were taken out on the corresponding day. Immunohistochemical results of $\alpha$-tubulin showed that all juveniles had a proper morphology and normal organization of the CNS and pharynx. And all animals have a similar mitotic activity. These results demonstrate that planarians can develop properly in altered gravity conditions, at least in the specific settings used in this experiment. And it called for further analysis for a more complete understanding if juveniles can survive longer times in the RPM $60^{\circ} / \mathrm{s}$ conditions [16].

In the research of $\mathrm{Lu}$ et al., they changed the gravity conditions through a large gradient high magnetic field (LG-HMF) and observed regeneration of planarians at three gravity levels (ug, 1g, and 2g). Their results demonstrate that all of the planarians normally regenerated their heads and the regeneration rate of the four groups is similar. These results indicate that planarians can correctly regenerate their heads at different gravity environments [25].

Sousa et al. in the European Space Research and Technology Centre (Noordwijk, The Netherlands) through the random positioning machine (RPM) simulated microgravity (the machine was set to a real random mode and random direction with a maximum speed of $10^{\circ} / \mathrm{s}$ ), and the large diameter centrifuge (LDC) generated hypergravity (8g). They put intact Schmidtea mediterranea planarians in the RPM and LDC at day 0 ; after 1 day, the planarians were amputated at pre- and postpharynx levels, and they collected trunk fragments and reloaded in the same devices. They found that all the planarian trunks exposed to s-ug or $8 \mathrm{~g}$ correctly regenerated the lost parts [26]. There are results showing that microgravity can induce developmental retardation and cell apoptosis of mouse embryos [27], and hypergravity conditions do not affect the normal development and actin filament structures of mouse embryos [28]. But microgravity can prevent terminal differentiation of embryonic stem cells $[29,30]$.

There are researchers that treat decapitated planarians with weak nonuniform magnetic fields (RMFs) and found RMFs eliminated the formation of edema and blastema, which through upregulating the expression of EGR4, Netrin 2, NSE, and NPY accelerates nerve cell proliferation and function recovery [31-33]. The weak magnetic field stimulates the fission frequency of the Planarian Dugesia (Girardia) tigrina [32]. Alanna et al. recently found that weak magnetic fields change the accumulation of reactive oxygen species (ROS), ERK cascade, and the expression of heat shock protein 70 (Hsp70) to regulate the proliferation and differentiation of stem cells $[34,35]$. The planarian will die suddenly when the geomagnetic activity is over K6 [36].

2.2. Behavior. In the experiment of Gorgiladze, the regenerated planarians have normal food behavior and locomotor activity; they can freely glide or alternate contraction and 
straightening of the body on the bottom of the flask or on the water surface [19]. Morokuma et al. had sent 5 tubes with different numbers of whole worms to the ISS and found that only the sample which contains 10 whole worms that had been launched into space showed immediate unusual behavior. They curled up ventrally and are somewhat paralyzed and immobile, when they had been introduced into fresh Poland spring water. They all regained normal behavior after 2 hours. And water shock was not seen in the other samples. These results indicate that microgravity can yield different effects according to different microenvironments of culture systems. After 20 months of return to Earth, the two groups of worms showed a comparable motion rate under the stimulation of red and blue light, and the control worms spent more time in the dark compared to the space-traveled worms [20].

$\mathrm{Lu}$ et al. found that the planarians which regenerated heads in different gravity conditions showed similar photonegative response. During the photonegative test, most of the regenerated planarians could reach the target quadrant in $90 \mathrm{~s}$, and the average times spent in the target quadrants did not significantly differ. These results showed that LGHMF-generated microgravity and hypergravity did not affect the reestablishment of photonegative ability. But the photonegative response time of the planarians which regenerated under LG-HMF conditions was slightly suppressed, and the authors thought it was mainly due to the difference of the locomotor system instead of the reconstructed head [25]. They took the traditional planarian locomotor velocity (pLMV) assay and automated center-of-mass (COM) tracking approach and image analysis to analyze the locomotor behaviors, and the results showed that Group ug/12T has a significantly decreased locomotor function compared to the other three groups during the 8 min test. And the righting time of the simulated microgravity group also showed significantly increased compared to the other groups, but the planarians could eventually sense the reverse direction and complete the correction of the body, indicating that the function of the nervous system was normal. Histologic section staining and immunohistochemistry results showed that the circular muscle of planarians regenerated in simulated microgravity was weakened compared with the other planarian groups, and the fluorescence thickness of the epithelial cilia are significantly decreased. The authors thought that differences in locomotion velocity and righting behavior come from frail muscle [25]. There is research showing that planarian that has been exposed to $16 \mathrm{G}$ intensity static magnetic fields for one day significantly improved the velocity of movement [37].

2.3. Transcriptomic. In the experiment of Sousa et al., they put intact Schmidtea mediterranea planarians in the RPM and LDC at day 0. After 1 day, the planarians were amputated at pre- and postpharynx levels, and they collected trunk fragments and reloaded in the same devices. Five and 12 days after amputation, they collected all kinds of samples, respectively, and analyzed the transcriptome of each sample. The principal component analysis (PCA) showed that the same time samples were clustered together and the same gravity condition samples were also clustered together. They found that after $12 \mathrm{dR}$ (13 days of s-ug or $8 \mathrm{~g}$ exposure), several genes were deferentially expressed in exposed animals compared to their corresponding controls. The number of differentially expressed genes was much higher in animals regenerating in s-ug conditions than in animals regenerating at $8 \mathrm{~g}$, and there is a much higher number of deregulated genes (720 versus 77) [26].

Regarding the specific deregulated genes at s-ug, they found the downregulation of cytoskeleton and matrix genes-such as collagen-a-1, piwi genes, and the upregulation of genes which are involved in ribosome biogenesis. What makes them confused is that although supporting higher mechanical forces require strengthening the cell cytoskeleton to maintain the shape and function, they did not find significant alteration of cytoskeleton or matrix proteins in planarians regenerating at $8 \mathrm{~g}$ conditions. Their results indicate that altered gravity conditions can severely affect genetic transcription, and these alterations potentiate molecular disorders which could promote the development of multiple diseases such as cancer [26].

2.4. The Others. In the study of Morokuma et al., the microbiome profiles of those culture-based are significantly different. In space-exposed worms, the number of colonies of Variovorax, Herminiimonas, and the unknown Comamonadaceae decreased and the number of Chryseobacterium colonies significantly increased. Their results indicate that space travel can change bacterial community composition of $D$. japonica, and this difference can exist for a few years. And they analyzed the samples of the water of the space-exposed worms and the Earth-only with liquid chromatographymass spectrometry (LC-MS); the results revealed that both samples contained a large number of small organic molecules/metabolites. The total ion chromatograms of the two samples in the positive ion mode were quite different, and many of them correspond to long-chain fatty acids or monohydroxylated/dihydroxylated long-chain fatty acids [20].

\section{Physiological Effects of Temperature and Oxygen}

Temperature and oxygen are the other important factors of the environment, which can affect, regulate, and control lots of biological and pathological processes of organisms $[6,38-$ 40]. For organisms, sensing the temperature and oxygen of the environment is very important for them to adjust behavioral strategy and escape injury. There are researchers reporting that nutrition and temperature can impact the oxygen consumption and metabolic status and impact the process of development, regeneration, injury, and escape from noxious stimulation, etc. [41-44]. And environmental stress can, through a conserved pathway, impact the biological process from planarian to human. In this session, we will discuss the impact of temperature and oxygen on planarian.

3.1. The Regeneration and Fission Ability. People found that the ROS production takes part in the regeneration in zebrafish and Xenopus $[45,46]$. But the limited regeneration ability of these organisms restricted researchers that deeply explore 
the function and impact of ROS in regeneration. Planarians are famous for their amazing regeneration ability; they can easily regenerate any parts of the body and include a functional head, and the new head can even have the memory of the former brain. These characters make these worms to be an ideal model.

Every live organisms need energy to maintain the function of cells; hence, every living cell needs to consume oxygen to keep the balance of metabolism. There are researches reporting that small planarians have a higher oxygen consumption rate, and injured planarians have a lower oxygen consumption rate, but injured worms have increased glycolysis during the process of regeneration [47]. Pirotte et al. researched the impact of ROS on planarian regeneration with Schmidtea mediterranea. They amputate the planarian into three fragments at pre- and postpharynx levels and research the impact of ROS to different part regeneration. They found that ROS burst just in a few minutes after amputation, and the production of ROS is independent of the orientation of the wound site, but it induced signals to regulate the regeneration process which appears at least after $24 \mathrm{~h}$ from amputation. Inhibition of the production of ROS leads to failure to regenerate the lost parts of all three fragments, and they found that reduced ROS restricted the regeneration of cephalic ganglia and the ectopic neuronal cells. And they found that disturbing the production of ROS did not affect the stem cell proliferation but restricted the neoblast differentiation into the required cell types of regeneration [48]. In addition, there are works that suggest that increased ROS do not accelerate the aging of mice and some long life-span mammals have a higher level of ROS and oxidative damage $[49,50]$. Literatures showed that human protein has Met and Cyst residues, and these residues through trapping oxygen atoms prevent ROS-induced neuronal cell death $[51,52]$. Tsushima et al. found that the protein of DJ- 1 is conversed from human to planarian, especially the important residues for function execution; they knock down the DJ-1 gene in vivo through RNAi, and the results showed that planarian DJ-1 has antioxidant and neuroprotective functions; it indicates that planarian can be a reliable model for study oxidative stress-introduced disorders and offer the chance to explore the mechanisms [53].

There is literature reporting intact planarian preference to move to the cooler region, and even the amputated head fragment moved to the cold field [54]. It means that the head region can sense and responds to environment temperature in planarian and showed that DjTRPMa-expressing neurons sense the temperature and transduce signals to serotonergic neurons of the brain; then, serotonergic neurons exhibit thermotactic behavior. Ding et al. reported that Dugesia japonica planarian showed different regeneration speeds at different temperatures $\left(15^{\circ} \mathrm{C}, 20^{\circ} \mathrm{C}\right.$, and $\left.25^{\circ} \mathrm{C}\right)$; lower temperature decreased the regeneration speed [55]. The Schmidtea mediterranea trunk fragment can completely regenerate the head and tail at five days after amputation when cultured at $26^{\circ} \mathrm{C}$ and $28^{\circ} \mathrm{C}$ and shortened to two days compared with the planarian cultured at $19^{\circ} \mathrm{C}$. And the eyes appeared from three days postamputation when cultured at $26^{\circ} \mathrm{C}$ and $28^{\circ} \mathrm{C}$, but the control worms regenerated eyes at five days [56].
According to literatures showing that the fission of planarian flatworms correlates with the length and area size of worms [57], the fission frequency increased with the body size; when the body length is shorter than $4-5 \mathrm{~mm}$, they cannot fission again [58]. Subsequent researchers reported that environmental stress can impact the process, such as increased temperature would decrease the fission length and increase the frequency of fission [59]. Hammoudi et al. showed that the spontaneous fission frequency multiplied significantly at $26^{\circ} \mathrm{C}$ and $28^{\circ} \mathrm{C}$ than at $19^{\circ} \mathrm{C}$ [56]. In addition, there have been reports that before the fission event, there was an increased proliferation of neoblast just like after amputation [60], and activating the mitotic functions through RNAi of DjP2X-A can induce higher fission frequency [61].

3.2. Behavior. Planarians can normally live and behave from $15^{\circ} \mathrm{C}$ to $25^{\circ} \mathrm{C}$, the locomotor activity has been strongly suppressed below $10^{\circ} \mathrm{C}$, the worms will lose their motility between 5 and $10^{\circ} \mathrm{C}$, and high temperature almost did not affect the mobility of planarians, but they will die in 1 hour when the temperature is above $30^{\circ} \mathrm{C}[54,56]$. Hammoudi et al. reported that slowly increasing the temperature of water can elongate the live times of planarians, but they cannot survive more than 20 days when the temperature is over $30^{\circ} \mathrm{C}$ [56]. From $7^{\circ} \mathrm{C}$ to $12^{\circ} \mathrm{C}$, the body of planarian has some contraction, movement is slow, and the velocity is not stable; when the temperature is between $12^{\circ} \mathrm{C}$ and $21^{\circ} \mathrm{C}$, the velocity gradually increased to its maxim value and the body stretched along the anterior-posterior axis which probably extended 25 per cent compared with that at $10^{\circ} \mathrm{C}$. Above $21^{\circ} \mathrm{C}$, the locomotor rate becomes not constant again and the speed is no more than that at $21^{\circ} \mathrm{C}$. When the temperature increased to $30^{\circ} \mathrm{C}$, the worms become motionless [62].

Ding et al. showed that suitable living temperatures can accelerate the toxic effect of $\mathrm{Fe}^{3+}$. They observed the toxic effect of $\mathrm{Fe}^{3+}$ for planarian at three different temperatures $15^{\circ} \mathrm{C}, 20^{\circ} \mathrm{C}$, and $25^{\circ} \mathrm{C}$ and found that the death speed increased at $20^{\circ} \mathrm{C}$ and showed the lowest death speed at $15^{\circ} \mathrm{C}$ [55]. Normally, dorsal epidermis of planarians has excretory pores, hair cells, and rhabdites and can secrete droplets and generate mucus. The structure of epidermis has been damaged when the temperature increased over $33^{\circ} \mathrm{C}$ for Girardia tigrina and $37^{\circ} \mathrm{C}$ for Girardia sp. There were fewer rhabdites and fewer and disorganized secretory droplets [63], which form the mucus to help planarians to respond and escape stress [64, 65].

Higher temperatures did not impact the feeding behavior of planarians from $19^{\circ} \mathrm{C}$ to $28^{\circ} \mathrm{C}$ [56]; the ability to eliminate bacteria of planarians at different temperatures changed. After infection with $10^{9} \mathrm{CFU}$ of $S$. aureus for three hours, the worms need six days to eliminate the bacteria at $19^{\circ} \mathrm{C}$ and just need three days when they had been cultured at $28^{\circ} \mathrm{C}$. It means that planarians have exacerbated antibacterial capabilities with the increase of temperature from $19^{\circ} \mathrm{C}$ to $28^{\circ} \mathrm{C}[56]$. The eye action potential (OP) that evoked by a light flash in the planarian changed with the temperature. When the temperature increased from $15^{\circ} \mathrm{C}$ to $23^{\circ} \mathrm{C}$, the amplitude increased and the latency and peak delay decreased; as the 
TABLE 1: Some major advances of the effect of extreme environmental stress on planarians.

\begin{tabular}{|c|c|c|}
\hline Stress conditions & The main impact on planarian & References \\
\hline \multicolumn{3}{|c|}{ The effects of gravity and magnetic field } \\
\hline Microgravity (space) & $\begin{array}{l}\text { All the amputated body parts regenerated the } \\
\text { lost fragments. }\end{array}$ & Gorgiladze [19] \\
\hline Microgravity (space) & $\begin{array}{l}\text { The whole worms had spontaneous fission. The pharynx } \\
\text { fragment had regenerated two heads and grew more } \\
\text { slowly. Some whole worms showed immediate unusual } \\
\text { behavior. The microbiome profiles had changed. }\end{array}$ & Morokuma et al. [20] \\
\hline Microgravity (RPM 60\% $/ \mathrm{s})$ & The trunk planarians had died. & Adell et al. [16] \\
\hline Microgravity (RPM $\left.10^{\circ} / \mathrm{s}\right)$ & The trunk planarians appeared normally regenerated. & \\
\hline Hypergravity (LDC 3g, 4g) & $\begin{array}{l}\text { The amputated body parts regenerated the missing } \\
\text { tissues; the proliferation rate was decreased. }\end{array}$ & \\
\hline Hypergravity (LDC 8g) & $\begin{array}{c}\text { Only the larger trunk planarian fragments can } \\
\text { regenerate the lost part. }\end{array}$ & \\
\hline Microgravity (LG-HMF ug) & $\begin{array}{c}\text { The amputated body parts normally regenerated their } \\
\text { heads. The worms have a significantly decreased } \\
\text { locomotor function. }\end{array}$ & Lu et al. [25] \\
\hline Hypergravity (LG-HMF 2g) & $\begin{array}{c}\text { The amputated body parts normally regenerated } \\
\text { their heads. }\end{array}$ & \\
\hline Microgravity (RPM 10\%s) & $\begin{array}{l}\text { The body parts properly regenerated head. Cytoskeleton } \\
\text { and matrix genes had been downregulated. }\end{array}$ & Sousa et al. [26] \\
\hline Hypergravity (LDC 8g) & $\begin{array}{l}\text { The body parts properly regenerated head. } \\
\text { Microtubules, cell communication, and cell cycle genes } \\
\text { had been downregulated. }\end{array}$ & \\
\hline Weak magnetic field & $\begin{array}{c}\text { The nerve cell proliferation has been accelerated. } \\
\text { The regeneration speed increased. The frequency } \\
\text { of spontaneous increased. The velocity of } \\
\text { movement improved. }\end{array}$ & $\begin{array}{l}\text { Novikov et al. [32], Gang et al. [33]. } \\
\text { Gang and Persinger [37] }\end{array}$ \\
\hline Intense magnetic field & The planarian will suddenly die when it is over $6 \mathrm{~K}$. & Murugan et al. [36] \\
\hline \multicolumn{3}{|c|}{ The effects of oxygen and temperature } \\
\hline Inhibit ROS & $\begin{array}{l}\text { Planarian fragments fail to regenerate the lost parts. The } \\
\text { regeneration of cephalic ganglia and ectopic neuronal } \\
\text { cells had been restricted. Neoblast differentiation has } \\
\text { been restricted. }\end{array}$ & Pirotte et al. [48] \\
\hline Increase ROS & Induce damage of DNA, lipids, and proteins. & Finkel [68] \\
\hline Lower temperature $\left(15^{\circ} \mathrm{C}\right)$ & $\begin{array}{l}\text { The regeneration speed decreased. The spontaneous } \\
\text { fission frequency increased. The movement is slow, } \\
\text { and the velocity is not stable. The toxic effect of } \mathrm{Fe}^{3+} \text { has } \\
\text { been decreased. }\end{array}$ & $\begin{array}{l}\text { Ding et al. [55], Hammoudi et al. [56], } \\
\text { Herath and Lobo [59], Cole [62] }\end{array}$ \\
\hline Higher temperature $\left(25-33^{\circ} \mathrm{C}\right)$ & $\begin{array}{l}\text { The regeneration speed increased. The movement is } \\
\text { slow, and the velocity is not stable. The secretory } \\
\text { function has been restricted. The capability to eliminate } \\
\text { balance increased. }\end{array}$ & $\begin{array}{l}\text { Ding et al. [55], Hammoudi et al. [56], } \\
\text { Cole [62], Oliveira et al. [63] }\end{array}$ \\
\hline
\end{tabular}

temperature is greater than $30^{\circ} \mathrm{C}$, the amplitude decreased and latency and peak delay continued to decrease until $42^{\circ} \mathrm{C}$. These changes can be reversible when the temperature is lower than $30^{\circ} \mathrm{C}[66]$.

Ectothermic organisms respond to altered temperatures through adjusting their biochemical process but not through changing their body temperature [67]. One of the important strategies is through changing the mitochondrial oxidative phosphorylation (OXPHOS) pathways to survive, which is critical to provide energy for the eukaryotic cells. Hence, OXPHOS is important in balancing the process of metabo- lism and the generation of reactive oxygen species (ROS). And moderate ROS is necessary for lots of important biological processes, but overproduced ROS can damage DNA, lipids, and proteins [68]. It means temperature changes OXPHOS to modify the production of ROS and then affect the signals of cells $[69,70]$. Animals can respond to temperature through two steps, one is the phosphorylation system and the other is the complex I of the NADH pathway [7175]. After 4 weeks of acclimation under low temperature, planarians can effectively increase the capacity of these related proteins [75]. 


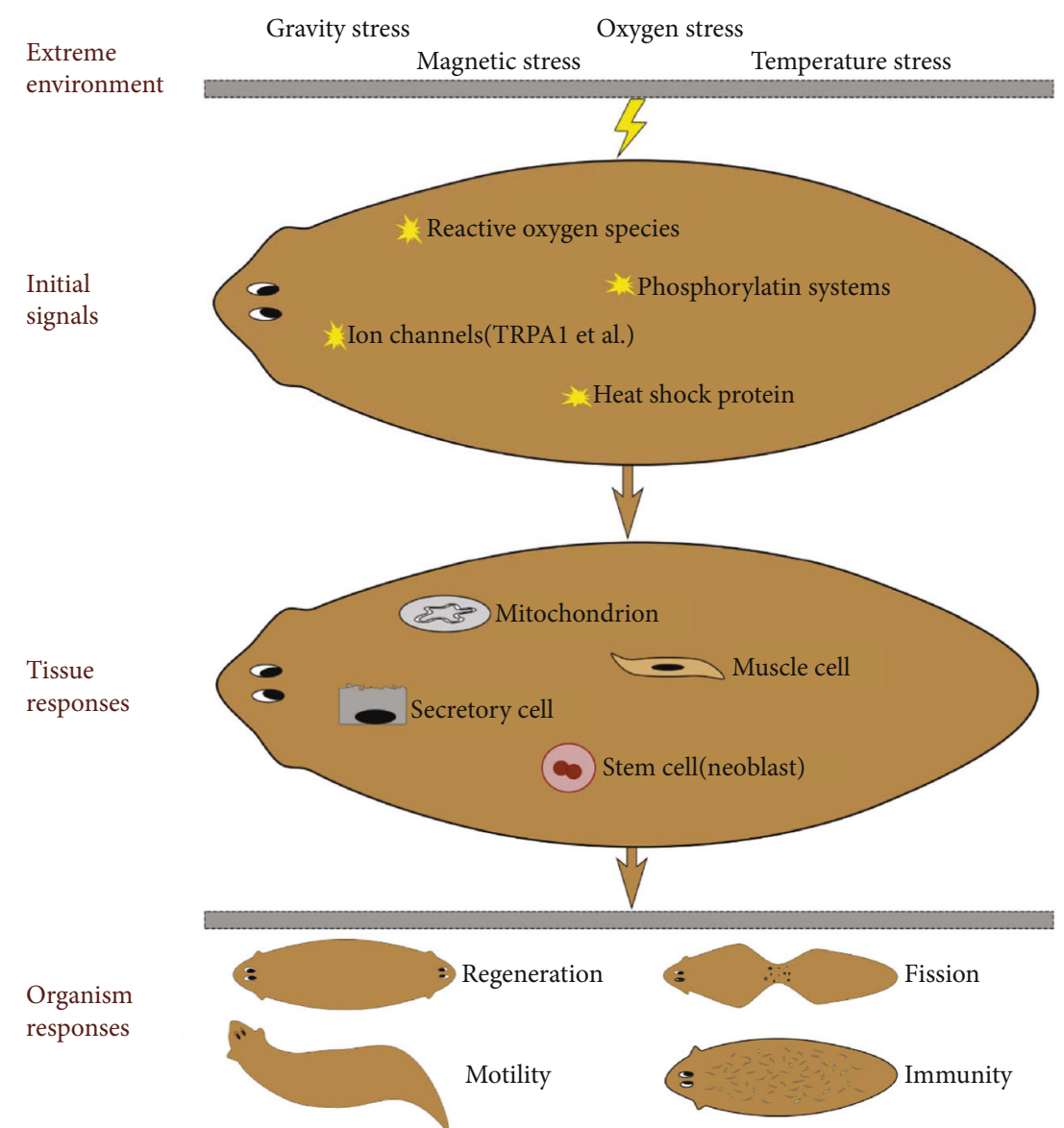

Figure 2: The effects of extreme environmental stress on planarians. Different kinds of extreme environmental factors irritate planarian; organisms sense it and produce the initial signal molecules (yellow star), then recruit more respond factors to join the war and change the metabolism status of different cells and organelles; at last, the organism showed changed regeneration ability, fission frequency, mobility, and immunity.

3.3. The Molecular Response. There is literature showing that the conserved ion channel TRPA1 exhibit important function to feel noxious heat and start the protective behavior [76], but Arenas et al. showed that TRAP1 cannot be directly activated by heat; they found that heat induces the production of ROS and then through RTPA1 regulates the escape process in Schmidtea mediterranea planarian [77]. Disturbing the regeneration of ROS or the expression of RTPA1 can lead to failure of avoiding noxious heat.

When the temperature increased to $25^{\circ} \mathrm{C}$, the expression of $\mathrm{DjH}$ H990 protein upregulated approximately 2 -fold compared with that cultured at $18^{\circ} \mathrm{C}$. When the temperature increased to $32^{\circ} \mathrm{C}$, the $\mathrm{DjH} H \mathrm{sp} 90$ protein level decreased lower than normally $\left(18^{\circ} \mathrm{C}\right)$ cultured planarians, but the level of Djhsp 90 mRNA is still higher at $32^{\circ} \mathrm{C}$. It means that high temperature firstly restricted the process of posttranscription events [78]. Immunohistochemistry showed that the Djhsp90-positive cells distributed in parenchymal tissue from head to tail, just under the epidermis cells, indicating that they are suitable to sense and respond to the external environmental signals [78]. When temperature changed (increase or decrease), head-expressed DjSpsb mRNA will increase in Dugesia japonica [79]. The levels of putrescine and spermidine are also temporarily increased after heat shock or cold shock, which is essential for planarian to recover from damage [80].

\section{The Controversial Issues and Future Directions}

People created different experiments to explore the impact of extreme environmental stress on planarians and had obtained lots of valuable information (Table 1). But there are still some controversial issues that need to be noted and improved in future research.

4.1. Planarian Species and Planarian Density. In different researches, people used different planarian species, such as Schmidtea mediterranea, Dugesia tigrina, and Dugesia japonica. Jason et al. had reported that even though different species share similar anatomy and mode of reproduction, they find that each species had acquired its own distinct strategy for optimizing its reproductive success [81]. The other question is the density of planarian. In present reports, the researchers placed different numbers of planarian in a single tube and resulted in different densities of worms in each 
experiment. And the density of worms can impact the fission and the expression of some molecules. This makes it complicated to directly compare the results. We need to take into account the impact of planarian species and planarian density if we want to get more reliable and to directly compare data.

4.2. The Methods and Strategies to Change Environmental Stress. Just as mentioned above, researchers use different strategies and methods to change the environment station. And these differences can lead to inconsistent results, such as the fact that the same microgravity conditions in RPM $60 \%$ can lead to the death of regenerated planarians but not in $10^{\circ} / \mathrm{s}$; slowly increasing the temperature to $30^{\circ} \mathrm{C}$ makes planarian live longer times. Further analysis showed that the rheoreceptors of the intact head induced the death of planarians in RPM $60^{\circ} / \mathrm{s}$ but not the microgravity. When analyzing the effects of given environmental stress, we need to be cautious to the results and carefully consider the method and strategy to change the stress condition.

4.3. The Crosstalk of Different Environmental Stress. Existing research showed that microgravity did not induce failure of regeneration, but the regeneration becomes slow. And microgravity increased the spontaneous fission frequency and changed the microbiome profiles of planarian. They curled up and are immobile in spring water when they returned to Earth from space, then slowly recover to normal mobility after two hours. Researchers did not find upregulated genes of cytoskeleton or matrix related to hypergravity which has been supposed to maintain shape and strength of the cytoskeleton of cells. Temperature and oxygen are important environmental factors; oxygen is necessary for almost all animals. Research showed that temperature can impact the oxygen consumption and metabolic status, impact regeneration capacity and fission frequency, and even regulated the capacity to eliminate bacteria. Just as Figure 2 shows that different environmental factors irritate organisms, organisms sense it and produce the initial signal molecules, then recruit more response factors to join the war and change the metabolism status, protein expression levels, cell structures, and so on; at last, the organism exhibits the environmental stress effects, such as changed regeneration ability, fission frequency, mobility, and immunity. Different environmental factors can generate cross effects; there are researches showing that late loading and early retrieval can increase the success of life science experiments in space [82, 83]. Long time cold storage will increase the death frequency and induce fail of regeneration [84].

\section{Conclusion}

The relatively simple planarian offered a unique opportunity to study the physiological and behavioral process and to investigate the mechanisms underlying different environmental stress in whole animals. It is more helpful to understand the overall response of the organisms to facing different environmental stress than specific tissues. These could provide us with important insights about basic molecular processes occurring in a wide range of vertebrates, including humans. But present researches analyzed the morphological and physiological changes more than molecular mechanisms, and some researches even get conflicting results for the same stress condition. These results call for further experiments to carefully consider the cross effects of different environmental stress and deeply detect the molecular mechanisms. It is still an exciting era for researchers.

\section{Conflicts of Interest}

The authors declare that they have no conflicts of interest.

\section{Acknowledgments}

This research was supported by the National Natural Science Foundation of China (grants 31701308 to Z.C. and 31572263 to B.Z.) and Shandong Province Natural Science Foundation (grant ZR2014DM015 to X.Z.).

\section{References}

[1] J. J. Collins, X. Hou, E. V. Romanova et al., "Genome-wide analyses reveal a role for peptide hormones in planarian germline development," PLoS Biology, vol. 8, no. 10, article e1000509, 2010.

[2] K. Mineta, M. Nakazawa, F. Cebria, K. Ikeo, K. Agata, and T. Gojobori, "Origin and evolutionary process of the CNS elucidated by comparative genomics analysis of planarian ESTs," Proceedings of the National Academy of Sciences of the United States of America, vol. 100, no. 13, pp. 7666-7671, 2003.

[3] S. Fraguas, S. Barberán, B. Ibarra, L. Stöger, and F. Cebri, "Regeneration of neuronal cell types in Schmidtea mediterranea: an immunohistochemical and expression study," The International Journal of Developmental Biology, vol. 56, no. 1-2-3, pp. 143-153, 2012.

[4] H. B. Sarnat and M. G. Netsky, "The brain of the planarian as the ancestor of the human brain," The Canadian Journal of Neurological Sciences, vol. 12, no. 4, pp. 296-302, 1985.

[5] K. Agata, Y. Soejima, K. Kato, C. Kobayashi, Y. Umesono, and $\mathrm{K}$. Watanabe, "Structure of the planarian central nervous system (CNS) revealed by neuronal cell markers," Zoological Science, vol. 15, no. 3, pp. 433-440, 1998.

[6] P. W. Reddien and A. S. Alvarado, "Fundamentals of planarian regeneration," Annual Review of Cell and Developmental Biology, vol. 20, no. 1, pp. 725-757, 2004.

[7] D. J. Forsthoefel and P. A. Newmark, "Emerging patterns in planarian regeneration," Current Opinion in Genetics \& Development, vol. 19, no. 4, pp. 412-420, 2009.

[8] E. Salo, J. F. Abril, T. Adell et al., "Planarian regeneration: achievements and future directions after 20 years of research," The International Journal of Developmental Biology, vol. 53, no. 8-9-10, pp. 1317-1327, 2009.

[9] D. D. R. Brown and B. J. Pearson, “A brain unfixed: unlimited neurogenesis and regeneration of the adult planarian nervous system," Frontiers in Neuroscience, vol. 11, p. 289, 2017.

[10] A. Sanchez Alvarado, "Planarian regeneration: its end is its beginning," Cell, vol. 124, no. 2, pp. 241-245, 2006.

[11] J. C. Buckey, Space Physiology. Oxford, Oxford University Press, New York, 2006. 
[12] G. C. Demontis, M. M. Germani, E. G. Caiani, I. Barravecchia, C. Passino, and D. Angeloni, "Human pathophysiological adaptations to the space environment," Frontiers in Physiology, vol. 8, p. 547, 2017.

[13] D. Sarkar, T. Nagaya, K. Koga, and H. Seo, "Culture in vectoraveraged gravity environment in a clinostat results in detachment of osteoblastic ROS 17/2.8 cells," Environ Med, vol. 43, no. 1, pp. 22-24, 1999.

[14] B. M. Uva, M. A. Masini, M. Sturla et al., "Clinorotationinduced weightlessness influences the cytoskeleton of glial cells in culture," Brain Research, vol. 934, no. 2, pp. 132139, 2002.

[15] A. Sundaresan, D. Risin, and N. R. Pellis, "Loss of signal transduction and inhibition of lymphocyte locomotion in a groundbased model of microgravity," In Vitro Cellular \& Developmental Biology. Animal, vol. 38, no. 2, pp. 118-122, 2002.

[16] T. Adell, E. Saló, J. J. W. A. van Loon, and G. Auletta, "Planarians sense simulated microgravity and hypergravity," BioMed Research International, vol. 2014, 10 pages, 2014.

[17] X. Lei, Z. Deng, H. Zhang et al., "Rotary suspension culture enhances mesendoderm differentiation of embryonic stem cells through modulation of Wnt/ $\beta$-catenin pathway," Stem Cell Reviews and Reports, vol. 10, no. 4, pp. 526-538, 2014.

[18] X. Lei, Y. Cao, B. Ma et al., "Development of mouse preimplantation embryos in space," National Science Review, 2020.

[19] G. I. Gorgiladze, "Regenerative capacity of the planarian Girardia tigrina and the snail Helix lucorum exposed to microgravity during an orbital flight on board the International Space Station," Doklady Biological Sciences, vol. 421, no. 1, pp. 244247, 2008.

[20] J. Morokuma, F. Durant, K. B. Williams et al., "Planarian regeneration in space: persistent anatomical, behavioral, and bacteriological changes induced by space travel," Regeneration (Oxf), vol. 4, no. 2, pp. 85-102, 2017.

[21] M. Levin, J. Morokuma, and J. Finkelstein, "Space travel has effects on planarian regeneration that cannot be explained by a null hypothesis," Regeneration (Oxf), vol. 4, no. 4, pp. 156158, 2017.

[22] C. Papaseit, N. Pochon, and J. Tabony, "Microtubule selforganization is gravity-dependent," Proceedings of the National Academy of Sciences of the United States of America, vol. 97, no. 15, pp. 8364-8368, 2000.

[23] S. J. Crawford-Young, "Effects of microgravity on cell cytoskeleton and embryogenesis," The International Journal of Developmental Biology, vol. 50, no. 2-3, pp. 183-191, 2006.

[24] D. Vorselen, W. H. Roos, F. C. MacKintosh, G. J. L. Wuite, and J. J. W. A. Loon, "The role of the cytoskeleton in sensing changes in gravity by nonspecialized cells," The FASEB Journal, vol. 28, no. 2, pp. 536-547, 2014.

[25] H.-M. Lu, X.-L. Lu, J.-H. Zhai et al., "Effects of large gradient high magnetic field (LG-HMF) on the long-term culture of aquatic organisms: planarians example," Bioelectromagnetics, vol. 39, no. 6, pp. 428-440, 2018.

[26] N. de Sousa, G. Rodriguez-Esteban, I. Colagè et al., "Transcriptomic analysis of planarians under simulated microgravity or 8 $\mathrm{g}$ demonstrates that alteration of gravity induces genomic and cellular alterations that could facilitate tumoral transformation," International Journal of Molecular Sciences, vol. 20, no. 3, p. 720, 2019.

[27] Y. CAO, X. FAN, Z. SHEN, B. MA, and E. DUAN, "Nitric oxide affects preimplantation embryonic development in a rotating wall vessel bioreactor simulating microgravity," Cell Biology International, vol. 31, no. 1, pp. 24-29, 2007.

[28] L.-N. Ning, X.-H. Lei, Y.-J. Cao et al., "Effect of short-term hypergravity treatment on mouse 2-cell embryo development," Microgravity Science Technology, vol. 27, no. 6, pp. 465-471, 2015.

[29] X. Lei, Y. Cao, Y. Zhang et al., "Effect of microgravity on proliferation and differentiation of embryonic stem cells in an automated culturing system during the TZ-1 space mission," Cell Proliferation, vol. 51, no. 5, article e12466, 2018.

[30] X. Lei, Y. Cao, Y. Zhang, and E. Duan, “Advances of mammalian reproduction and embryonic development under microgravity," in Life Science in Space: Experiments on Board the SJ-10 Recoverable SatelliteResearch for Development, Spring, Singapore.

[31] Q. Chen, G. Lin, N. Wu et al., "Early exposure of rotating magnetic fields promotes central nervous regeneration in planarian Girardia sinensis," Bioelectromagnetics, vol. 37, no. 4, pp. $244-$ 255, 2016.

[32] V. V. Novikov, I. M. Sheiman, and E. E. Fesenko, "Effect of weak static and low-frequency alternating magnetic fields on the fission and regeneration of the planarian Dugesia (Girardia) tigrina," Bioelectromagnetics, vol. 29, no. 5, pp. 387-393, 2008.

[33] N. Gang, G. H. Parker, R. M. Lafrenie, and M. A. Persinger, "Intermittent exposures to nanoTesla range, $7 \mathrm{~Hz}$, amplitude-modulated magnetic fields increase regeneration rates in planarian," International Journal of Radiation Biology, vol. 89, no. 5, pp. 384-389, 2013.

[34] A. V. Van Huizen, J. M. Morton, L. J. Kinsey et al., "Weak magnetic fields alter stem cell-mediated growth," Science Advances, vol. 5, no. 1, p. eaau7201, 2019.

[35] R. Goodman, A. Lin-Ye, M. S. Geddis et al., "Extremely low frequency electromagnetic fields activate the ERK cascade, increase hsp70 protein levels and promote regeneration in Planaria," International Journal of Radiation Biology, vol. 85, no. 10, pp. 851-859, 2009.

[36] N. J. Murugan, L. M. Karbowski, W. F. Mekers, and M. A. Persinger, "Group planarian sudden mortality: is the threshold around global geomagnetic activity $\geq \mathrm{K} 6$ ? ," Communicative \& Integrative Biology, vol. 8, no. 6, article e1095413, 2015.

[37] N. Gang and M. A. Persinger, "Planarian activity differences when maintained in water pre-treated with magnetic fields: a nonlinear effect," Electromagnetic Biology and Medicine, vol. 30, no. 4, pp. 198-204, 2011.

[38] H. B. Lillywhite, "Temperature selection by the bullfrog, Rana catesbeiana," Comparative Biochemistry and Physiology. A, Comparative Physiology, vol. 40, no. 1, pp. 213-227, 1971.

[39] S. Bennett, C. M. Duarte, N. Marbà, and T. Wernberg, "Integrating within-species variation in thermal physiology into climate change ecology," Philosophical Transactions of the Royal Society of London. Series B, Biological Sciences, vol. 374, no. 1778 , p. 20180550, 2019.

[40] B. H. Brattstrom, "Thermal acclimation in anuran amphibians as a function of latitude and altitude," Comparative Biochemistry and Physiology, vol. 24, no. 1, pp. 93-111, 1968.

[41] M. Agathocleous and W. A. Harris, "Metabolism in physiological cell proliferation and differentiation," Trends in Cell Biology, vol. 23, no. 10, pp. 484-492, 2013.

[42] C. D. L. Folmes and A. Terzic, "Energy metabolism in the acquisition and maintenance of stemness," Seminars in Cell \& Developmental Biology, vol. 52, pp. 68-75, 2016. 
[43] J. K. Salabei, P. K. Lorkiewicz, C. R. Holden et al., "Glutamine regulates cardiac progenitor cell metabolism and proliferation," Stem Cells, vol. 33, no. 8, pp. 2613-2627, 2015.

[44] J. A. Gaspar, M. X. Doss, J. G. Hengstler, C. Cadenas, J. Hescheler, and A. Sachinidis, "Unique metabolic features of stem cells, cardiomyocytes, and their progenitors," Circulation Research, vol. 114, no. 8, pp. 1346-1360, 2014.

[45] C. Gauron, C. Rampon, M. Bouzaffour et al., "Sustained production of ROS triggers compensatory proliferation and is required for regeneration to proceed," Scientific Reports, vol. 3, no. 1, 2013.

[46] N. R. Love, Y. Chen, S. Ishibashi et al., “Amputation-induced reactive oxygen species are required for successful Xenopus tadpole tail regeneration," Nature Cell Biology, vol. 15, no. 2, pp. 222-228, 2013.

[47] E. A. Osuma, D. W. Riggs, A. A. Gibb, and B. G. Hill, "High throughput measurement of metabolism in planarians reveals activation of glycolysis during regeneration," Regeneration (Oxf), vol. 5, no. 1, pp. 78-86, 2018.

[48] N. Pirotte, A. S. Stevens, S. Fraguas et al., "Reactive oxygen species in planarian regeneration: an upstream necessity for correct patterning and brain formation," Oxidative Medicine and Cellular Longevity, vol. 2015, 19 pages, 2015.

[49] R. Doonan, J. J. McElwee, F. Matthijssens et al., "Against the oxidative damage theory of aging: superoxide dismutases protect against oxidative stress but have little or no effect on life span in Caenorhabditis elegans," Genes \& Development, vol. 22, no. 23, pp. 3236-3241, 2008.

[50] B. Andziak, T. P. O'Connor, W. Qi et al., "High oxidative damage levels in the longest-living rodent, the naked mole-rat," Aging Cell, vol. 5, no. 6, pp. 463-471, 2006.

[51] W. Zhou, M. Zhu, M. A. Wilson, G. A. Petsko, and A. L. Fink, "The oxidation state of DJ-1 regulates its chaperone activity toward $\alpha$-Synuclein," Journal of Molecular Biology, vol. 356, no. 4, pp. 1036-1048, 2006.

[52] T. Taira, Y. Saito, T. Niki, S. M. M. Iguchi-Ariga, K. Takahashi, and $\mathrm{H}$. Ariga, "DJ-1 has a role in antioxidative stress to prevent cell death," EMBO Reports, vol. 5, no. 2, pp. 213-218, 2004.

[53] J. Tsushima, K. Nishimura, N. Tashiro et al., "Protective effect of planarian DJ-1 against 6-hydroxydopamine-induced neurotoxicity," Neuroscience Research, vol. 74, no. 3-4, pp. 277-283, 2012.

[54] T. Inoue, T. Yamashita, and K. Agata, "Thermosensory signaling by TRPM is processed by brain serotonergic neurons to produce planarian thermotaxis," The Journal of Neuroscience, vol. 34, no. 47, pp. 15701-15714, 2014.

[55] X. Ding, L. Song, Y. Han et al., "Effects of Fe3+ on Acute Toxicity and Regeneration of Planarian (Dugesia japonica) at Different Temperatures," BioMed Research International, vol. 2019, 9 pages, 2019.

[56] N. Hammoudi, C. Torre, E. Ghigo, and M. Drancourt, "Temperature affects the biology of Schmidtea mediterranea," Scientific Reports, vol. 8, no. 1, p. 14934, 2018.

[57] J. B. Best, A. B. Goodman, and A. Pigon, "Fissioning in planarians: control by the brain," Science, vol. 164, no. 3879, pp. 565566, 1969.

[58] C. P. Arnold, B. W. Benham-Pyle, J. J. Lange, C. J. Wood, and A. Sánchez Alvarado, "Wnt and TGF $\beta$ coordinate growth and patterning to regulate size-dependent behaviour," Nature, vol. 572, no. 7771, pp. 655-659, 2019.
[59] S. Herath and D. Lobo, "Cross-inhibition of Turing patterns explains the self-organized regulatory mechanism of planarian fission," Journal of Theoretical Biology, vol. 485, p. 110042, 2020.

[60] D. Bueno, J. Fernàndez-Rodríguez, A. Cardona, V. Hernàndez-Hernàndez, and R. Romero, "A novel invertebrate trophic factor related to invertebrate neurotrophins is involved in planarian body regional survival and asexual reproduction," Developmental Biology, vol. 252, no. 2, pp. 188-201, 2002.

[61] T. Sakurai, H. Lee, M. Kashima et al., "The planarian P2X homolog in the regulation of asexual reproduction," The International Journal of Developmental Biology, vol. 56, no. 1-2-3, pp. 173-182, 2012.

[62] W. H. Cole, "Temperature and locomotion in planaria," The Journal of General Physiology, vol. 9, no. 4, pp. 503-511, 1926.

[63] M. S. de Oliveira, K. A. R. Lopes, P. M. S. C. M. Leite, F. V. Morais, and N. M. R. de Campos Velho, "Physiological evaluation of the behavior and epidermis of freshwater planarians (Girardia tigrinaandGirardiasp.) exposed to stressors," Biol Open, vol. 7, no. 6, p. bio029595, 2018.

[64] I. D. Bowen, T. A. Ryder, and J. A. Thompson, "The fine structure of the planarianPolycelis tenuis Iijima," Protoplasma, vol. 79, no. 1-2, pp. 1-17, 1974.

[65] L. R. Smales and H. D. Blankespoor, "The epidermis and sensory organs of Dugesia tigrina (Turbellaria: Tricladida). A scanning electron microscope study," Cell and Tissue Research, vol. 193, no. 1, pp. 35-40, 1978.

[66] H. M. Brown and T. E. Ogden, "The electrical response of the planarian ocellus," The Journal of General Physiology, vol. 51, no. 2, pp. 237-253, 1968.

[67] H. O. Portner, "Climate variations and the physiological basis of temperature dependent biogeography: systemic to molecular hierarchy of thermal tolerance in animals," Comparative Biochemistry and Physiology. Part A, Molecular \& Integrative Physiology, vol. 132, no. 4, pp. 739-761, 2002.

[68] T. Finkel, "Signal transduction by reactive oxygen species," The Journal of Cell Biology, vol. 194, no. 1, pp. 7-15, 2011.

[69] D. Abele, K. Heise, H. O. Pörtner, and S. Puntarulo, “Temperature-dependence of mitochondrial function and production of reactive oxygen species in the intertidal mud clam Mya arenaria," The Journal of Experimental Biology, vol. 205, Part 13, pp. 1831-1841, 2002.

[70] W. Jarmuszkiewicz, A. Woyda-Ploszczyca, A. Koziel, J. Majerczak, and J. A. Zoladz, “Temperature controls oxidative phosphorylation and reactive oxygen species production through uncoupling in rat skeletal muscle mitochondria," Free Radical Biology \& Medicine, vol. 83, pp. 12-20, 2015.

[71] E. Gnaiger, "Capacity of oxidative phosphorylation in human skeletal muscle," The International Journal of Biochemistry \& Cell Biology, vol. 41, no. 10, pp. 1837-1845, 2009.

[72] H. Lemieux, P. U. Blier, and E. Gnaiger, "Remodeling pathway control of mitochondrial respiratory capacity by temperature in mouse heart: electron flow through the Q-junction in permeabilized fibers," Scientific Reports, vol. 7, no. 1, p. 2840, 2017.

[73] H. Lemieux, S. Semsroth, H. Antretter, D. Höfer, and E. Gnaiger, "Mitochondrial respiratory control and early defects of oxidative phosphorylation in the failing human heart," The International Journal of Biochemistry \& Cell Biology, vol. 43, no. 12, pp. 1729-1738, 2011. 
[74] H. Lemieux and B. E. Warren, "An animal model to study human muscular diseases involving mitochondrial oxidative phosphorylation," Journal of Bioenergetics and Biomembranes, vol. 44, no. 4, pp. 503-512, 2012.

[75] K. Y. Scott, R. Matthew, J. Woolcock, M. Silva, and H. Lemieux, "Adjustments in the control of mitochondrial respiratory capacity to tolerate temperature fluctuations," Journal Experimental Biology, vol. 222, no. 18, p. jeb207951, 2019.

[76] M. Gallio, T. A. Ofstad, L. J. Macpherson, J. W. Wang, and C. S. Zuker, "The coding of temperature in the Drosophila brain," Cell, vol. 144, no. 4, pp. 614-624, 2011.

[77] O. M. Arenas, E. E. Zaharieva, A. Para, C. Vásquez-Doorman, C. P. Petersen, and M. Gallio, "Activation of planarian TRPA1 by reactive oxygen species reveals a conserved mechanism for animal nociception," Nature Neuroscience, vol. 20, no. 12, pp. 1686-1693, 2017.

[78] K. X. Ma, G. W. Chen, and D. Z. Liu, "cDNA cloning of heat shock protein 90 gene and protein expression pattern in response to heavy metal exposure and thermal stress in planarian Dugesia japonica," Molecular Biology Reports, vol. 39, no. 6, pp. 7203-7210, 2012.

[79] Z. Dong, F. Cheng, Y. Yuwen et al., "Identification and expression analysis of a Spsb gene in planarian Dugesia japonica," Gene, vol. 564, no. 2, pp. 168-175, 2015.

[80] K. Hamana, H. Hamana, and T. Shinozawa, "Alterations in polyamine levels of nematode, earthworm, leech and planarian during regeneration, temperature and osmotic stresses," Comparative Biochemistry and Physiology. Part B, Biochemistry \& Molecular Biology, vol. 111, no. 1, pp. 91-97, 1995.

[81] J. A. Carter, C. H. Lind, M. P. Truong, and E.-M. S. Collins, "To each his own," Journal of Statistical Physics, vol. 161, no. 1, pp. 250-272, 2015.

[82] M. Hughes-Fulford, "Lessons learned about spaceflight and cell biology experiments," Journal of Gravitational Physiology, vol. 11, no. 1, pp. 105-109, 2004.

[83] P. Warren, A. Golden, J. Hanover, D. Love, F. Shephard, and N. J. Szewczyk, "Evaluation of the fluids mixing enclosure system for life science experiments during a commercial Caenorhabditis elegans spaceflight experiment," Advances in Space Research, vol. 51, no. 12, pp. 2241-2250, 2013.

[84] Vista SSEP Mission 11 Team, D. Hagstrom, C. Bartee, and E.M. S. Collins, "Studying planarian regeneration aboard the International Space Station within the Student Space Flight Experimental Program," Frontiers in Astronomy and Space Sciences, vol. 5, 2018. 